\title{
Capítulo II \\ El Proceso de Institucionalización de la EIB en la Provincia de Cotopaxi
}

Sebastián Granda Merchán

\section{SciELO Books / SciELO Livros / SciELO Libros}

GRANDA MERCHÁN, S. El Proceso de Institucionalización de la EIB en la Provincia de Cotopaxi. In: Estado, educación y pueblos indígenas en los Andes ecuatorianos: la experiencia del Sistema de Escuelas Indígenas de Cotopaxi [online]. Quito: Editorial Abya-Yala, 2020, pp. 89-132. Investigación Decolonial series, n. 2. ISBN: 978-9978-10-457-6.

http://doi.org/10.7476/9789978105733.0004.

\section{(c) ()}

All the contents of this work, except where otherwise noted, is licensed under a Creative Commons Attribution 4.0 International license.

Todo o conteúdo deste trabalho, exceto quando houver ressalva, é publicado sob a licença Creative Commons Atribição 4.0.

Todo el contenido de esta obra, excepto donde se indique lo contrario, está bajo licencia de la licencia Creative Commons Reconocimento 4.0. 


\section{Capítulo II}

\section{EL PROCESO DE INSTITUCIONALIZACIÓN DE LA EIB EN LA PROVINCIA DE COTOPAXI}

En abril de 1989, seis meses después de promulgado el decreto de creación de la DINEIB, inició el proceso de institucionalización de la educación indígena en cada una de las dieciséis provincias que contaba con un porcentaje importante de esta población. Dicho proceso supuso la construcción de una jurisdicción propia para la educación de la población indígena, así como la creación de instancias de poder descentralizadas para su gestión y administración: las DIPEIB.

Este capítulo tiene como propósito analizar el proceso de institucionalización de la EIB en una de las provincias de la Sierra ecuatoriana: Cotopaxi; pues a partir de 1989 las escuelas del SEIC pasaron a formar parte de la jurisdicción de EIB de dicha provincia y quedaron sujetas a las políticas de la DIPEIB-C.

La hipótesis que sostenemos es que el proceso de institucionalización de la educación indígena derivó en la creación de una instancia de poder estatal paralela dentro del campo educativo ${ }^{49}$ de la provincia de Cotopaxi, que asumió el control de la educación indígena en la zona

49 Nos alineamos con el concepto de campo de Pierre Bourdieu, entendido como "una red de relaciones objetivas (de dominación o de subordinación, de complementariedad o antagonismo, etc.) entre posiciones [...]. Cada posición está objetivamente definida por su relación objetiva con las demás posiciones, o, en otros términos, por el sistema de propiedades pertinentes, es decir, eficientes, que permiten situarla con relación a todas las demás en la estructura de la distribución global de las propiedades" (Bourdieu 1995). 
y que, como consecuencia, centralizó varias funciones que antes estaban en manos de las comunidades y las escuelas indígenas.

Decimos que fue una instancia de poder estatal paralela por cuanto en Cotopaxi ya existía una instancia encargada de la gestión de la educación: la Dirección Provincial de Educación de Cotopaxi, que, con el proceso de institucionalización aludido, perdió el control de las escuelas indígenas y quedó a cargo, exclusivamente, de las escuelas y colegios de la población mestiza.

Para el desarrollo de este capítulo se utilizó información recopilada en fuentes primarias y secundarias, así como información levantada mediante entrevistas a profundidad aplicadas a actores clave. Entre las fuentes primarias constan los planes de trabajo de la Dirección Provincial, sus informes de gestión, informes de talleres y congresos realizados en la provincia; así como La Gazeta, periódico local de la provincia de Cotopaxi. ${ }^{50}$ Entre las fuentes secundarias constan textos académicos que se escribieron a finales de la década de los 80 y en el transcurso de los 90 sobre el proceso de desarrollo de la EIB en la provincia.

En cuanto a las entrevistas a profundidad, se conversó con dos actores clave en los inicios del proceso de institucionalización: Luis Montaluisa, primer director de la DINEIB y funcionario de esta hasta la actualidad, y Luis José Guanochanga, primer director de la DIPEIB-C y su funcionario hasta 2011, año el que aquella dejó de operar. Además, se entrevistó al resto de directores de la DIPEIB-C que, en orden cronológico, fueron: Ángel Tibán, Roberto Allauca, Édgar Guashca, Amable Hurtado, Hilda Chaluisa y Arturo Ashca. Por último, se dialogó con dos personas del SEIC que participaron activamente en los primeros momentos de vida de la Dirección Provincial: Mery Martínez y Fernando Garcés.

El capítulo se encuentra organizado en tres partes. En la primera se analiza, a manera de antecedente, la emergencia del movimiento indígena y el proceso de creación de la DINEIB. En la segunda parte se discute el proceso de creación y consolidación de la DIPIEB-C y los conflictos que aquello desató a nivel del campo educativo de Cotopaxi.

50 Se tuvo acceso al archivo de la Biblioteca del Municipio de Latacunga, en el que reposan los ejemplares de La Gazeta desde 1950. 
Y, en la última parte, se caracterizan las funciones que la DIPEIB-C pasó a desempeñar en el día a día y sus principales frentes de trabajo hasta su disolución en 2011.

\section{El movimiento indígena y la creación de la DINEIB}

1970 y 1980 fueron décadas trascendentes en la historia de la lucha de la población indígena, pues en estas emergió y se consolidó el movimiento indígena a nivel nacional (Sánchez Parga 2010). No queremos decir con ello que antes de la década de los 70 la población indígena no haya estado organizada y, menos aún, que no se hubiera movilizado en procura de sus derechos. De hecho, y como plantea Guerrero (1994), a lo largo de la época republicana, se dieron muchas movilizaciones indígenas, pero un elemento común de todas ellas fue que no lograron rebasar su ámbito, pues se dieron en el marco de las formaciones de poder local que se construyeron luego de la abolición del tributo indígena. En 1970 y 1980 emergió y se consolidó un movimiento indígena con carácter y alcance nacional, y con capacidad para interpelar de manera directa al Estado central.

La emergencia del movimiento indígena fue el resultado de una serie de cambios objetivos en el país, como el resquebrajamiento del sistema de hacienda por efecto de las reformas agrarias impulsadas en las décadas del 60 y 70 y la consecuente desestabilización del poder local; pero también de cambios de orden subjetivo, entre los que destacan el proceso de reinvención identitaria y un importante fortalecimiento organizativo (Granda 2003).

En relación con el proceso de reinvención identitaria, tenemos que la población indígena cuestionó las formas de representación con las que el Estado y la población blanco-mestiza les interpeló históricamente, y pasó a identificarse con nuevas formas: como nacionalidades indígenas, entendidas estas como un conjunto de "entidades históricas y políticas que constituyen el Estado ecuatoriano, que tienen en común una identidad, historia, idioma, cultura propia, que viven en un territorio determinado, mediante sus propias instituciones y formas tradicio- 
nales de organización social, económica, jurídica, política y ejercicio de autoridad propia” (CODENPE 1999).

Dicho proceso fue clave en la medida en que permitió a la población indígena contar con un paraguas identitario común, elemento central en la conformación de todo movimiento social; así como visibilizar y poner sobre la mesa sus derechos en tanto colectividades con una historia y cultura diferentes. Fue clave porque contribuyó a poner en cuestión el imaginario de Ecuador como "nación mestiza" y a redefinirlo como un Estado plurinacional, con todas las implicaciones que ello supone.

Respecto al segundo punto, en la década de 1930 se inició un intenso proceso de organización de la población indígena, como consecuencia de la comunalización a que dio lugar la Ley de Comunas (Sánchez Parga 2010). Dicho proceso continuó en las siguientes décadas, en el marco de la lucha por la tierra, con la creación de organizaciones de segundo grado y provinciales, y luego con la constitución de organizaciones de alcance regional, hasta desembocar, en 1986, en la creación de una sólida organización de carácter nacional: la CONAIE.

El tema del fortalecimiento organizativo fue crucial no solo porque contribuyó a quebrar el monopolio de la representatividad blanco-mestiza sobre la población indígena y la consecuente ventriloquía política que predominó en las décadas anteriores (Guerrero 1993), sino también y conectado con el punto anterior, porque potenció la capacidad de interlocución de la población indígena con el Estado y los diferentes actores de la sociedad civil.

Para fines de la década de los 80 , período en el que se dio el proceso de presión y negociación por la institucionalización de la EIB, el movimiento indígena se encontraba plenamente consolidado y había logrado definir los elementos centrales de su agenda política. Como veremos más adelante, fue justamente la CONAIE, en calidad de representante de la mayor parte de la población indígena del país, la que negoció con el Gobierno de la ID el tema de la creación de una estructura propia al interior del MEC para la gestión y desarrollo de la educación indígena en el país.

Desde el inicio, la educación fue un tema de suprema importancia para el movimiento indígena pues, al igual que en las décadas anteriores, 
se la consideraba un elemento central tanto para el afianzamiento de la identidad de la población indígena como para el fortalecimiento de sus organizaciones, aspectos nodales, desde el punto de vista de los líderes del momento, para su proceso de reconstitución como pueblos y nacionalidades y la lucha por sus derechos (DINEIB 1991).

Si bien es cierto que en los inicios la educación constituyó un elemento principal dentro de la agenda del movimiento indígena, además es cierto que el centro de su preocupación durante la década de 1980, y de manera especial en su segunda mitad, fue su control (Chiodi 1990), pues, debido a los problemas que las organizaciones indígenas vivieron en materia de participación en el marco del Programa de Alfabetización en Quichua impulsado por el Gobierno de Roldós-Hurtado, había la certeza al interior de la CONAIE de que la única manera de asegurar una educación acorde con los requerimientos de la población indígena era accediendo al control total y directo de ella y de sus diferentes componentes: la definición del currículo, la formación de los docentes y la elaboración de recursos educativos, entre otros.

En esta línea es interesante evidenciar cómo en julio de 1988, cuatro meses antes de que el Gobierno de la ID emitiera el decreto de creación de la DINEIB, y en una época de cada vez mayor movilización por parte de la población indígena, la CONAIE planteó al gobierno un conjunto de demandas de alto nivel entre las que constaban aquellas relacionadas con el tema educativo. De manera puntual, en el ámbito educativo las demandas de sus organizaciones eran dos: que se reconocieran y oficializaran los programas de educación indígena que operaban en el país, y que se reconociera a las organizaciones indígenas la potestad de dirigir y administrar dichos programas (Abya-Yala 1988).

\section{La creación de la DINEIB}

El 5 de noviembre de 1986 tuvo lugar el primer congreso pre CONAIE. En dicho congreso se fundó la CONAIE y se nombraron a las principales autoridades. Miguel Tankamash y José Jacinto Guamán fueron elegidos presidente y vicepresidente, respectivamente, de la naciente organización, y Luis Montaluisa fue designado director de Educación, 
Ciencia y Cultura, considerando su larga experiencia en el ámbito educativo y, de manera especial, su participación en el Programa de Alfabetización en Quichua.

Además de nombrar a los directivos, en el congreso se trataron varios temas entre los que constaba el educativo. Luis Montaluisa, flamante director de Educación, planteó dos puntos que fueron acogidos por unanimidad por todos los participantes: la necesidad de crear una instancia dentro del Estado para la gestión de la educación indígena, liderada por ellos mismos, y la creación de una universidad indígena. ${ }^{51}$

La creación de una instancia al interior del Estado para hacerse cargo de la gestión de la EIB, y en manos de los indígenas, era considerada una medida urgente por dos razones: para asegurar el control de la educación indígena por parte de sus organizaciones, por un lado, y para contrarrestar las trabas que continuamente ponía el MEC a las iniciativas de la población indígena en materia educativa, por el otro. ${ }^{52}$

Sobre primer punto, como resultado de los problemas que se vivieron en el marco del Programa de Alfabetización en Quichua en materia de participación de las organizaciones indígenas, se tenía la certeza de que la única manera de asegurar el desarrollo de una educación acorde con los intereses de la población indígena era acceder a su control directo y total. Aquello suponía no solo contar con una instancia propia al interior del Estado, sino también que esta fuera controlada por las organizaciones indígenas.

Con respecto al segundo punto, el Programa de Alfabetización en Quichua fue para el equipo gestor una experiencia negativa a nivel de lo que significaba trabajar al interior del Estado, pues fueron muchas las ocasiones en que, desde diferentes instancias del MEC, se terminaba bloqueando o dilatando las iniciativas. Los funcionarios de la DINEIB explican la problemática de la siguiente manera:

Veíamos que en el Ministerio de Educación, en las Direcciones Provinciales, hacer que se apruebe un texto, no digamos un curriculum, un texto, que se aprueben los contenidos, era prácticamente imposible.

51 Luis Montaluisa, entrevista personal, 20 de marzo de 2013, Quito.

52 Ibíd. 
Porque se enviaba, y a mí me tocó hacer esto, cuando trabajábamos en la Universidad Católica en el último período, se enviaba un material para que el Ministerio lo revise, porque querían aprobar supuestamente. Pasaban seis meses y eso se había empolvado y decían bueno no entendemos. Después había que ir a explicarles, decirles vea así es, estos materiales son así, eso es lo que se está enseñando. “¡Ah! pero no está de acuerdo a los programas oficiales”. Y ahí moría todo. Si se quería organizar una escuela, ellos tenían el poder de no permitirlo. Y recuerdo muy bien que en la comunidad de la provincia de Tungurahua, en Caua Chico, la policía fue a cerrar la escuela. Porque ellos tenían el poder. Si queríamos nombrar profesores bilingües, peor todavía porque ellos decidían sobre las partidas. Ahí se vio la necesidad de responder poco a poco con una instancia organizada. (DINEIB 1991)

Las trabas fueron asumidas por los líderes indígenas no solo como un problema técnico o burocrático, sino como un problema fundamentalmente político, pues eran vistas como una expresión más de la discriminación desplegada por la población blanco-mestiza hacia la población indígena, un intento más de bloquear las iniciativas de la población indígena orientadas a resarcir su histórica exclusión.

Con el visto bueno del Congreso de la CONAIE, se inició el lento y engorroso trabajo encaminado a conseguir que el Gobierno de Rodrigo Borja aprobara la creación de una dirección de educación indígena al interior del Estado, trabajo que recayó sobre la Dirección de Educación de la CONAIE. El trabajo contempló dos frentes: el diálogo con las comunidades indígenas, por un lado, y el cabildeo y negociación con los representantes del gobierno de turno, por otro.

Con relación al primer frente, en el transcurso de los siguientes meses se realizaron reuniones con los dirigentes de educación de las diferentes provincias y nacionalidades para socializar el tema y buscar estrategias para institucionalizar la educación. De igual manera, se visitó a una gran cantidad de comunidades de la Costa, Sierra y Oriente, y se organizaron varias reuniones con dirigentes indígenas provinciales y nacionales con el objetivo de socializar la propuesta de creación de una dirección de educación indígena y conocer el punto de vista de la población y los dirigentes. ${ }^{53}$ 
La propuesta fue bien recibida solo en ciertos sectores, debido a que la institucionalización era vista como un serio riesgo para las organizaciones indígenas, por cuanto podía implicar que el movimiento indígena pasara a estar controlado por el Estado y los gobiernos de turno. Tal era el recelo que en ese momento generaba el tema de los procesos de institucionalización en los líderes indígenas que ni siquiera la ECUARUNARI ni la misma CONAIE se animaban a tramitar su personería jurídica por el temor a ser cooptados (Montaluisa 2008).

Sobre el segundo frente, el trabajo implicó la construcción y movilización de toda una red de relaciones sociales para llegar hasta el ministro de Educación y presentar la propuesta, aspecto de no fácil consecución si se considera que, hasta ese momento, muy pocas veces los líderes indígenas y políticos blanco-mestizos se habían sentado a dialogar sobre temas de interés nacional.

En el proceso de cabildeo y negociación fueron clave ciertos aliados del movimiento indígena, así como también ciertos funcionarios del gobierno de turno. En el caso de los aliados merecen destacarse personajes como Ileana Almeida, académica que, desde tiempo atrás, apoyaba a las organizaciones indígenas y que sirvió de puente entre el director de Educación de la CONAIE y el ministro de Educación y Cultura. En el ámbito del gobierno fue clave el rol del ministro de Educación, Alfredo Vera, así como el del asesor en asuntos indígenas de la Presidencia: Alfonso Calderón. Ambos funcionarios apoyaron de diferente manera el proyecto de la población indígena y generaron los espacios necesarios para que la CONAIE socializara la propuesta al interior del ministerio.

Asimismo fue clave, como veremos más adelante, el capital social y simbólico (Bourdieu 2000) con el que contaban ciertos líderes indígenas que participaron directamente en los procesos de negociación. Este era el caso, por ejemplo, de Luis Montaluisa, que tenía reconocimiento por su trayectoria en el ámbito de la educación indígena y sus aportes académicos; y que contaba con una red de relaciones que incluía a personas del sector blanco-mestizo vinculados tanto a la academia como al ámbito de la política nacional. Es necesario destacar estos elementos puesto que, en el día a día, fueron estos recursos y la habilidad en su 
puesta en práctica lo que permitió que las negociaciones llegaran a un buen fin, en un contexto de mucha hostilidad hacia la población indígena por parte de la población blanco-mestiza.

Tres eventos fueron decisivos en el proceso de cabildeo y negociación. El primero fue aquel en el que el director de Educación de la CONAIE y el ministro de Educación se conocieron e iniciaron las conversaciones sobre la posible dirección de educación indígena, evento de no fácil consecución y en el que tuvo una participación clave Ileana Almeida. Leamos el relato del director de Educación de la CONAIE sobre el encuentro:

Luego vino el triunfo del Dr. Rodrigo Borja en la segunda vuelta. Entonces traté de buscar contactos con el nuevo Gobierno, pero fue difícil. Ileana Almeida me facilitó el contacto con el arquitecto Alfredo Vera, que estaba ya designado como ministro de Educación y Cultura. Alfredo Vera me recibió en la casa de Guayasamín. Le presenté una copia del libro Comunidad, escuela y currículo, que acababa de publicar la UNES$\mathrm{CO}$ en Chile, y también una copia de un cuento ilustrado en lengua paikoka, traducido a siete lenguas indígenas y al español [...]. Le dije que las nacionalidades indígenas estábamos haciendo estos trabajos científicos y educativos sin apoyo del Estado, pero le expliqué que con apoyo del Estado podíamos avanzar más. Esto le emocionó. Me preguntó sobre lo que era la CONAIE pues, por ser originario de Guayaquil, no conocía el proceso organizativo de los indígenas. Me dijo que al otro día fuera a verlo con los otros dirigentes. (Montaluisa 2008, 64-5)

El segundo evento de relevancia constituyó la reunión oficial entre los funcionarios de la CONAIE y el ministro de Educación. Por pedido de la CONAIE, el ministro recibió en su despacho al presidente y vicepresidente de la confederación, así como a su director de Educación. En dicha reunión se habló nuevamente de la importancia de la educación indígena y de la necesidad de que su gestión pasara a manos de la población indígena. Al finalizar la reunión, el ministro se comprometió a crear la dirección de educación indígena.

Y, el tercer evento constituyó el "debate" organizado por el ministro de Educación entre los funcionarios de su ministerio y los de la CONAIE. La razón del inesperado "debate" tenía que ver con la gran oposición que se había generado al interior del ministerio en torno a la 
creación de la dirección de educación indígena. Montaluisa comenta lo siguiente sobre el tema:

Transcurrieron los meses de agosto y septiembre, y ya estábamos en octubre de 1988, pero el ministro no daba señales de concretar la creación de la DINEIB. Ante esto, con el asesor del presidente, el Dr. Alfonso Calderón Cevallos, acudí donde el ministro y le manifesté la preocupación por la demora en el trámite. Allí me enteré de la gran oposición que se había generado al interior del Ministerio de Educación y Cultura.

El director de Educación Compensatoria, ahora llamada Educación Popular Permanente, a pesar de ser socialista, junto con la directora de Educación Regular, cuyos nombres a propósito omito, lideraban la oposición a la creación de la DINEIB. Habían presentado al ministro un documento con treinta y siete argumentos para sostener su oposición. Algunos de los argumentos planteaba que, con su creación, se iba a dividir al país, que el sistema de educación es único, que no había indígenas preparados para administrar la educación, etc.

Ante esto, el ministro tomó la decisión de organizar un debate entre tres representantes de los funcionarios del ministerio que se oponían a la creación de la DINEIB y tres representantes de la CONAIE. El acuerdo era: si durante el debate los representantes de la CONAIE desvirtuaban los argumentos de quienes se oponían a su creación y lograban convencerlos de su conveniencias, entonces se creaba la DINEIB; caso contrario, no sería aprobada. $(2008,65)$

Dos días después de su anuncio el "debate" entre los funcionarios de ambas instancias tuvo lugar en las instalaciones del ministerio. En ningún momento tuvo lugar el mentado debate, pues los funcionarios del ministerio que se oponían al tema dieron, de entrada, su visto bueno a la creación de la dirección de educación indígena.

Rescatamos los tres eventos anteriores por cuanto dan una idea del trabajo minucioso que los líderes indígenas tuvieron que llevar adelante para alcanzar el visto bueno para la institucionalización de la EIB; y porque ayuda a visualizar las estrategias políticas micro de las organizaciones indígenas, dimensión muy a menudo dejada de lado en los análisis que se hacen sobre sus luchas y logros.

Luego del mencionado debate y por pedido del asesor jurídico del ministro, la CONAIE preparó la propuesta borrador del decreto ejecutivo de creación de la dirección de educación indígena, la que recibió 
el visto bueno por parte de la asesoría jurídica de la Presidencia. Finalmente, el decreto fue firmado el 9 de noviembre de 1988 y publicado en el Registro Oficial el 15 de noviembre del mismo año.

Con el decreto ejecutivo en cuestión, se reformó radicalmente el Reglamento General de la Ley de Educación del momento. El decreto promulgó la creación de la DINEIB, ${ }^{54}$ y responsabilizó a dicha instancia de la "planificación, organización, dirección, control, coordinación y evaluación de la educación indígena en los sistemas escolarizado y no escolarizado" (Presidencia de la República 1988). Entre las atribuciones que se le asignó a dicha dirección estaban las siguientes:

- Planificar, dirigir y ejecutar la educación indígena.

- Formar y capacitar profesores y demás recursos humanos para la educación indígena en las diferentes lenguas del país.

- Organizar los establecimientos de educación indígena bilingüe en los niveles preprimario, primario y medio.

- Realizar el seguimiento y la evaluación de la educación indígena.

- Coordinar y controlar la educación indígena bilingüe.

- Detectar las necesidades cuantitativas y cualitativas de recursos humanos, materiales y de infraestructura educativa indígena [...].

- Establecer canales de comunicación con la representación de las nacionalidades indígenas.

- Promover la producción y utilización de materiales didácticos de acuerdo con los criterios lingüísticos, pedagógicos y sociales adecuados.

- Velar por la aplicación de una política lingüística que tome en cuenta un sistema de escritura unificada para cada lengua, basado en lo posible en el criterio fonológico.

- Impulsar programas de educación no escolarizada relacionados con la cultura indígena.

- Diseñar modalidades educativas acordes con las necesidades de la población indígena. 
- Desarrollar un currículo apropiado para cada uno de los subsistemas y modalidades de educación indígena.

- Organizar programas acelerados de formación de maestros indígenas de acuerdo con las características y necesidades de las diversas comunidades indígenas.

- Dirigir y organizar y ejecutar la alfabetización y educación de adultos bilingüe.

- Dirigir, organizar y orientar la educación de los normales bilingües.

- Determinar y coordinar con la DINACE y la DINADER la construcción de las infraestructuras escolar y deportiva, respectivamente. (Presidencia de la República 1988)

Además, el decreto estipuló los requerimientos necesarios a nivel de estructura para el cumplimiento de las atribuciones arriba señaladas. Así, por ejemplo, con relación a la organización del sistema educativo, se dispuso la creación de dos subsistemas de educación escolarizada: el hispano y el indígena. Lo mismo para el caso del subsistema de educación no escolarizada. En el ámbito de la supervisión educativa se contempló la creación de un departamento de supervisión para la educación hispana y un departamento de supervisión para la educación indígena. De igual manera, se estipuló que la formación de los docentes de la educación intercultural bilingüe pasara a manos de los normales bilingües y multilingües, los que, a su vez, dependerían de la DINEIB.

Como se puede constatar, las funciones y atribuciones delegadas a la DINEIB cubrían un espectro bastante amplio, pues incluía todos aquellos aspectos sensibles y necesarios para la gestión y control de la educación de la población indígena, desde la creación de un currículo apropiado y la producción de los materiales didácticos necesarios, pasando por la formación de los docentes y su seguimiento en el aula, hasta la organización de los establecimientos educativos.

Es interesante constatar el hecho de que con el decreto se entregó a los indígenas el control sobre las dos modalidades educativas en las que dicha población había incursionado en las últimas décadas: la educación escolarizada y la no escolarizada, así como el hecho de que, en el 
caso de la modalidad escolarizada, se le entregó el control de todos los niveles: preprimaria, primaria y secundaria; quedando fuera únicamente la educación superior. Por otro lado, es interesante evidenciar, con González (2011), que con la creación de la DINEIB las organizaciones indígenas pasaron a tener un control de alcance nacional, que incluía a todas aquellas iniciativas educativas impulsadas por las organizaciones y comunidades indígenas a lo largo y ancho del país.

La experiencia de la institucionalización de la EIB en Ecuador ha sido única en América Latina, pues a diferencia de otros países en los que la educación indígena alcanzó el estatus de un programa o un proyecto de Estado, en Ecuador la educación indígena terminó convirtiéndose en un subsistema paralelo al subsistema educativo previamente existente, con lo cual el sistema educativo ecuatoriano quedó partido en dos: el subsistema de educación hispana, por un lado, con sus propios directivos y equipo de trabajo, su propios estudiantes e instituciones educativas, su propio currículo y sus propios docentes e institutos de formación docente; y el subsistema de educación intercultural bilingüe, por otro, con los mismos elementos.

Mucho se ha discutido en Ecuador y la región sobre este formato de institucionalización de la educación indígena. Las voces más críticas han considerado que aquello fue un suicidio político por cuanto, en ese momento, la población indígena no contaba con los recursos humanos ni la experiencia y conocimiento necesarios para hacerse cargo de tan grande empresa; $y$ también por el riesgo de terminar generando un "apartheid educativo". Entre las personas que se han alineado con esta perspectiva están los funcionarios del mismo Ministerio de Educación de diferentes gobiernos; pero incluso ciertos líderes indígenas que no pertenecen a la CONAIE y que han visto en esta modalidad una estrategia para profundizar la distancia entre la población indígena y el resto de la sociedad ecuatoriana. También ha sido la perspectiva de algunos intelectuales que han acompañado de cerca al movimiento indígena en su apuesta por una educación diferente. Un ejemplo de estos últimos es Matthias Abram, que ya para 1989, meses después de que se había promulgado el decreto de creación de la DINEIB, planteaba su preocupación en los siguientes términos: 
Los indígenas de la Sierra no están preparados para hacerse cargo de toda la educación primaria, menos aún de la educación a varios niveles. No hay maestros, no hay profesionales capaces de cubrir los campos necesarios para hacer una educación funcional, liberadora y creativa, También hay vacíos en lo que se refiere a la necesidad de abordar los diferentes campos de investigación [...]. Hasta aquí estamos hablando de educación bilingüe en un contexto de completa ausencia de bilingüismo a nivel social. Es además un bilingüismo educativo unilateral. No existe la más mínima preocupación de la otra parte, la mestiza, de aprender el kichwa [...]. Una etnoeducación a cargo de las organizaciones indígenas nos parece el instrumento de un progresivo apartheid, sin la garantía de un nivel pedagógico y científico claro [...]. Nos parece por lo tanto que la lucha no es obtener la educación en autogestión, sino crear al interior del sistema educativo, alternativas de educación intercultural bilingüe. (Chiodi 1990, 378)

En el otro lado están las voces que plantean que aquel formato de institucionalización fue un acierto político, en la medida en que era la única vía, y lo sigue siendo hasta el momento actual, dirán, de asegurar el control de la educación por parte de la población indígena, y ligado a esto, de asegurar una educación con pertinencia lingüística, cultural y social. En esta línea están varios de los líderes indígenas que vivieron y apoyaron el proceso, y que hasta el día de hoy cuestionan la disolución de dicha estructura. Además, se ubican en esta línea ciertos sectores de la intelectualidad indígena y no indígena cercana al movimiento indígena como, por ejemplo, Floresmilo Simbaña, Armando Muyolema, Pablo Dávalos o la misma Ileana Almeida. Para este grupo de líderes e intelectuales el problema no fue el formato con el que se institucionalizó la educación indígena, sino fundamentalmente que el Estado no respaldó, como debía, el proceso de desarrollo y consolidación de la EIB en el país $\mathrm{y}$ en las diferentes provincias.

Ahora bien, desde el punto de vista de la organización del Estado, vemos que se optó por un esquema de carácter multicultural, ${ }^{55}$ que apostó

55 Nos alineamos con el concepto de multiculturalismo que maneja Catherine Walsh, y que podría resumirse como aquel proyecto que busca "reconocer, tolerar e incorporar lo diferente dentro de la matriz y estructuras establecidas" (Walsh 2009, 43). 
por la "inclusión” de la educación indígena en la estructura educativa ya existente y que, lejos de propiciar una reestructuración de la educación a nivel nacional, terminó generando un parasistema educativo.

Lo interesante a destacar es que dicho esquema no solo fue la manera en que el Estado respondió a la demanda de las organizaciones indígenas, sino que fue el esquema que la misma CONAIE tenía en mente como estrategia para pasar a controlar la educación de la población indígena. Para ese momento su meta no era transformar la educación del país, sino acceder al control de la educación de la población indígena y, por esa vía, asegurar una educación apropiada para aquella.

Respecto a este punto, conviene recordar con Walsh (1999) que en los inicios del movimiento indígena, y en especial durante la década de los 80, la interculturalidad era entendida más en términos de fortalecimiento de la propia cultura, de desarrollo endógeno, que en el sentido que luego el mismo movimiento indígena dio a la interculturalidad, a saber: un "proyecto político-ideológico que, con sus planteamientos sociales, políticos y jurídicos, pretende construir una verdadera democracia basada en la igualdad, la justicia y la unidad en la diversidad" $(1999,41)$.

Con la creación de la DINEIB se cerró un ciclo importante de lucha del movimiento indígena en materia educativa, pues constituyó la consecución de una de las demandas centrales del movimiento indígena durante la década de los 80: el control directo y total de la educación de la población indígena.

De la misma forma, con la creación de la DINEIB se abrieron retos inmensos para la CONAIE y la población indígena del país, pues se trataba de construir un subsistema de educación diferenciado para el conjunto de la población indígena a nivel nacional, aspecto que, como vimos, significaba, entre otras cosas, montar una nueva estructura al interior del Ministerio de Educación para la gestión, crear las direcciones provinciales, armar los equipos de gestión y la planta docente, asumir el control de los institutos de formación docente, definir la propuesta de su formación y crear una nueva propuesta curricular para los niveles preprimario, primario y secundario. 


\section{Creación y consolidación de la DIPEIB-C}

La construcción del subsistema de EIB a nivel nacional contempló el desarrollo de ciertas tareas de carácter urgente, entre las que se incluye la estructuración de las DIPEIB en aquellas provincias en las que, de acuerdo al diagnóstico del momento, había instituciones educativas que atendían a población indígena. La creación de las DIPEIB constituía un tema prioritario para el equipo central por cuanto eran las instancias ejecutivas encargadas de impulsar el desarrollo de la EIB en sus respectivos territorios, bajo los parámetros y lineamientos de la Dirección Nacional..$^{56}$

Una rápida lectura al orgánico funcional de la DINEIB de 1990 nos da una idea de la gran responsabilidad asignada a las direcciones provinciales, así como de las delicadas funciones a ellas encomendadas, entre las que destacan el tema de la contratación de los docentes y su despido, su formación, el desarrollo curricular, la generación de materiales didácticos, la supervisión y la evaluación del impacto de la EIB, (DINEIB 1990).

Al igual que en el nivel nacional, el proceso de creación de las DIPEIB tuvo que enfrentar muchos retos y fue altamente conflictivo. En lo que sigue haremos referencia a la creación de la dirección y la jurisdicción de EIB en la provincia de Cotopaxi, por cuanto, como ya señalamos, las escuelas del SEIC quedaron adscritas a dicha jurisdicción y tuvieron que lidiar con los cambios que aquello supuso. ${ }^{57}$

El primer reto de la DINEIB a nivel de Cotopaxi, al igual que en las demás provincias, fue la designación del director provincial. A pesar de que Cotopaxi constituía una de las provincias pioneras en el tema de la educación indígena, no contaba con los recursos humanos idóneos para asumir el cargo de director. Para el cargo se requerían personas que, además de haber estado vinculados con las experiencias de educación indígena y fueran bilingües, tuvieran al menos formación de bachi-

56 Luis Montaluisa, entrevista personal, 20 de marzo de 2013, Quito.

57 El siguiente capítulo está destinado a analizar cómo las escuelas del SEIC vivieron el proceso de adscripción a la jurisdicción de EIB de Cotopaxi y los cambios que aquello supuso en su dinámica cotidiana. 
llerato. Algunos de los docentes de las escuelas del Proyecto EIB sí tenían título de bachiller, pero carecían de la perspectiva política necesaria para impulsar una propuesta educativa alternativa. Los educadores comunitarios de las Escuelas Indígenas del Quilotoa, en cambio, contaban con la perspectiva política y la experiencia necesarias pero carecían de título de bachiller, pues, para ese entonces, la mayoría recién cursaba el ciclo básico (Martínez y Burbano 1994).

El proceso de selección estipulaba que las organizaciones indígenas de cada provincia debían sugerir los potenciales candidatos para el cargo de director provincial y que la DINEIB era la encargada de seleccionar al que mejor cumplía con los requerimientos estipulados. En el caso de Cotopaxi, sin embargo, el MICC no estuvo en condiciones de hacerlo debido al distanciamiento que en ese momento vivía con respecto al tema educativo, razón por la cual los candidatos fueron presentados por el mismo equipo del SEIC (F. Ante 1993).

El SEIC propuso tres candidatos para el cargo de director provincial: Pablo Ante, Daniel Semanate y Luis José Guanochanga, todos educadores de las escuelas del proyecto. De estos tres, Pablo Ante fue el elegido por la DINEIB por cuanto era el que mejor cumplía con el perfil buscado, pero debido a que no contaba con título de bachiller (estaba recién cursando el quinto curso), se designó como director temporal a Luis José Guanochanga, que en ese momento laboraba como educador comunitario en la zona de Panyatug (F. Ante 1993).

Para Luis José Guanochanga su designación como director provincial fue una sorpresa total, $y$, de un momento a otro, tuvo que dejar la escuela comunitaria en la que la que laboraba para trasladarse a Latacunga y asumir las nuevas funciones. Leamos como el mismo Guanochanga relata el acontecimiento:

Para mí fue una sorpresa la designación, no sé cómo sería. En ese tiempo yo estaba dando clases en Panyatug, eran épocas de Pascuas y estábamos de vacaciones. Yo estaba en la casa de mis padres, en Pucayacu, y en eso entra mi tío Manuel Guamangate, que trabajaba en las Escuelas Indígenas, y me dice: "a usted le llama padre Pepe, que el martes de tal fecha tiene que estar en Latacunga porque viene una funcionaria de 
Quito a posesionar como director de ni sé qué”. Yo, totalmente inocente, no sabía de qué me estaba hablando, ni lo que era.

Entonces salí y llegué a Latacunga a las 8 de la mañana, a las oficinas de la Dirección hispana. Justo me encontré con una señora de Otavalo que no le conocía. Ella había sido funcionaria de la DINEIB, la licenciada Lourdes Conterón. Entonces entramos a donde el licenciado Mario Vicente Herrera, el director hispano, y ahí la licenciada nos dijo que yo iba a hacerme cargo de la dirección provincial de educación intercultural bilingüe. Para el director hispano también fue una sorpresa mi designación. En esa época yo tenía veintitrés o veinticuatro años, y solo tenía experiencia como profesor; como administrador, ni idea. ${ }^{58}$

La posesión tuvo lugar el 19 de abril de 1989 en Quito, cinco meses después de la promulgación del decreto de creación de la DINEIB, con la presencia de las autoridades máximas de la CONAIE, funcionarios del gobierno de turno y miembros de su partido; en un ambiente de muchos ofrecimientos y optimismo para la educación indígena. La Gazeta, periódico local de la provincia de Cotopaxi, registró el evento de posesión de la siguiente manera:

Se posesionó director de Educación Inter-Cultural Bilingüe de Cotopaxi.

En acto cumplido el pasado día miércoles en el local del Ministerio de Educación, se posesionó como director provincial de Educación Intercultural Bilingüe de Cotopaxi, el señor profesor José Guanochanga, quien recibió la credencial correspondiente de su nombramiento de manos del Dr. Trajano Andrade, subsecretario de Educación.

"El sol de mediodía ha aparecido en medio de esta noche de oscurantismo y opresión” manifestó el señor Cristóbal Tapuy, director nacional de Comunidades Indígenas al expresar su reconocimiento por la iniciativa desplegada por el gobierno, tendiente a oficializar la educación en cada una de las culturas autóctonas.

A la posesión del flamante director provincial de Educación Intercultural Bilingüe de Cotopaxi asistió una nutrida concurrencia de militantes del partido de gobierno; el legislador Edwin Chamorro comprometió todo su contingente y ayuda a fin de que la acción educativa del profesor José Guanochanga sea el mejor mecanismo para rescatar a las poblaciones indígenas del anonimato y abandono en la que se encuentran 
sumergidas, lo que mereció favorable acogida de la delegación de Cotopaxi, quienes ratificaron su confianza de que se siga trabajando por todos los sectores, especialmente de los más necesitados. (La Gazeta 1989)

Como ocurrió a nivel nacional, en los inicios la Dirección Provincial no contó ni con una oficina para el desarrollo de sus labores, a pesar de que se había dado la disposición desde el MEC para que en las instalaciones de las direcciones provinciales hispanas se habilitara un espacio para el director y el equipo de las flamantes DIPEIB. Debido a lo anterior, la Dirección Provincial inició su trabajo en una oficina prestada de la Casa Campesina Juan Pablo Segundo, oficina utilizada igualmente por el equipo del SEIC..$^{59}$

Una vez designado el director y una vez que se contaba con un espacio para el trabajo, el reto inmediato era la conformación del equipo para llevar adelante las diferentes actividades encargadas a la dirección. En un primer momento el equipo estuvo conformado por tres personas, además del director, todas ellas vinculadas a las experiencias de educación indígena que se venían gestando en la provincia desde tiempo atrás. Rodrigo Martínez era un profesional mestizo que venía trabajando desde hace varios años en el proyecto de las escuelas del SEIC como asesor y formador de los educadores comunitarios y también dando clases. Ángel Rafael Cornejo venía de la experiencia del proyecto de EIB (financiado por la Cooperación Alemana) y, en el momento de la creación de la DIPIEB, fue transferido desde la Dirección Provincial hispana donde trabajaba como supervisor. Y, por último, Segundo Feliciano Tercero era el coordinador provincial de la Campaña de Alfabetización Monseñor Leonidas Proaño y vicepresidente del MICC. ${ }^{60}$

Conforme se organizó el trabajo al interior de la dirección y ganó claridad, se fueron armando equipos de trabajo para sus diferentes funciones (gestión de recursos humanos, supervisión, formación docente, etc.), con lo cual el equipo de la dirección creció considerablemente. El proceso de selección de los funcionarios se hacía vía consulta a las 
organizaciones indígenas provinciales y de segundo grado, incluso por medio de sugerencias de alguno de los miembros del equipo inicial que, durante el tiempo de trabajo, había conocido a muchos cuadros. ${ }^{61}$

Un tema que vale mencionar con relación a este punto es que, en los inicios, no se podía contratar a profesionales de fuera del sistema educativo para conformar los diferentes equipos de trabajo de la Dirección Provincial, puesto que no se contaba con partidas para aquello. Debían, necesariamente, buscar a personas que laboraran como profesores en cualquiera de las escuelas de la zona, con nombramiento, para solicitar el pase administrativo. Incluso podían ser profesores que estuvieran laborando en el equipo de funcionarios de la Dirección Provincial hispana, como fue el caso de Segundo Feliciano Tercero, a quien dieron el visto bueno para pasar a laborar en la DINEIB. ${ }^{62}$

Para 1993, cuatro años después de su creación, la Dirección Provincial estaba organizada en tres departamentos: el Administrativo, el Financiero y el Técnico-Pedagógico. El departamento Técnico-Pedagógico era el más grande e incluía cinco unidades de trabajo: Formación y mejoramiento docente, Currículo intercultural bilingüe, Educación popular permanente, Seguimiento y evaluación, y Cultura. El director provincial era asistido por un Comité de coordinación, por un lado, y por un Equipo de planeamiento, por otro (F. Ante 1993).

Es interesante anotar que la estructura organizativa de la Dirección Provincial, similar a lo que ocurría con la Dirección Nacional, era muy parecida a la de las direcciones provinciales hispanas, lo cual evidencia la poca capacidad de decisión que la Dirección Provincial tenía en ciertos temas. Evidenciamos este punto por cuanto uno de los directores provinciales entrevistados puso sobre la mesa el hecho de que en su período quiso cambiar la estructura organizativa de la Dirección Provincial por una que hubiera permitido realizar un trabajo más eficaz, pero fue negada su propuesta. ${ }^{63}$

61 Luis José Guanochanga, entrevista personal, 11 de abril de 2013, Latacunga.

62 Ibíd.

63 Roberto Allauca, entrevista personal, 18 de abril de 2013, Latacunga. 
El proceso de conformación y consolidación del equipo de la Dirección Provincial contempló procesos de capacitación permanente del personal, para lo cual se aprovechó de la experiencia y conocimientos de Rodrigo Martínez, miembro del equipo, e incluso de las capacitaciones que organizaba la DINEIB para los flamantes funcionarios de las direcciones provinciales. Las capacitaciones en dicho momento versaban fundamentalmente sobre el modelo de EIB y todo lo que tenía que ver con él (fundamentos, métodos, bilingüismo, etc.), y sobre temas administrativos y de legislación, de suprema importancia para la gestión del día a día de los funcionarios. ${ }^{64}$

El otro reto de la Dirección Provincial en los inicios, además de la conformación y consolidación del equipo de trabajo, era la definición de su jurisdicción y el consecuente proceso de selección de escuelas, que era un tema sensible pues se trataba, en última instancia, de definir el ámbito sobre el cual la Dirección Provincial podía ejercer el control, tema medular en el marco de la propuesta del movimiento indígena y la CONAIE.

Ahora bien, la selección de las instituciones educativas de la jurisdicción de EIB no estuvo en manos de las direcciones provinciales (se lo hizo desde la Dirección Nacional), pero sí la definición de la lista de escuelas que debían pasar a la jurisdicción, previa visita y consulta in situ con las comunidades, y siempre y cuando cumplieran con el criterio fijado por la misma Dirección Nacional, a saber, que al menos el 80 \% de los estudiantes de la institución tenía que ser bilingüe (DINEIB 1991).

El 12 de enero de 1989, tres meses después de la expedición del decreto de creación de la DINEIB, se generó la primera lista de las instituciones educativas y centros de alfabetización de la jurisdicción de EIB. Para la provincia de Cotopaxi se seleccionó un total de 300 instituciones educativas, entre las que estaban incluidas las escuelas del SEIC y las del proyecto de EIB (DINEIB 1991).

Con la lista en mano, el trabajo de la Dirección Provincial consistió en visitar a cada una de las comunidades de las escuelas seleccionadas para notificarles la decisión y explicar a los dirigentes y padres de familia sobre las ventajas de la EIB y de formar parte de la nueva 
jurisdicción. En el caso de las escuelas del SEIC y del proyecto de EIB, la visita no fue necesaria, pues el SEIC fue uno de los impulsores de la creación de la DINEIB, mientras que las escuelas del proyecto de EIB pasaron automáticamente a formar parte de ella. ${ }^{65}$

Como era de esperarse las reacciones de las escuelas fueron de diferente tipo. Mientras muchas de ellas estaban conformes y entusiasmadas con la idea de pasar a formar parte de la jurisdicción de EIB, otras se opusieron radicalmente a la propuesta. De acuerdo con los funcionarios de la DINEIB, entre los argumentos más comunes que justificaban la oposición se encontraban los siguientes:

1. La educación bilingüe en un retroceso al pasado.

2. El deseo de educarse en castellano, conocer la ciencia universal. El kichwa, por ser lengua ya conocida se consideraba innecesaria en la escuela.

3. El kichwa es un idioma muerto.

4. El deseo de aprender inglés en vez de kichwa.

5. El fomento del racismo con la educación bilingüe. (DINEIB 1991)

La oposición de las instituciones educativas y los argumentos que la respaldaron fueron fruto, en buena parte, de una campaña generalizada en contra de la EIB por parte de los profesores de la jurisdicción hispana y, de manera especial, de un grupo importante de profesores hispanos que no querían pasar a recibir órdenes de indígenas, y/o que veían que el paso de sus escuelas a la jurisdicción de EIB ponía en riesgo su posición y el poder que habían logrado al interior de las comunidades. Los funcionarios de la DINEIB explican dicha problemática en los siguientes términos:

A esta campaña [de desprestigio de la EIB] se sumó la oposición ciega de algunos sectores de profesores hispanos que, lejos de ser agentes de la promoción de la cultura y la ciencia, se habían transformado en dominadores de las comunidades. Efectivamente el estatus de profesor en las comunidades les permitía influir en la mayor parte de sus decisiones. Al producirse el proceso de la educación bilingüe ciertos espacios de poder en las comunidades, que eran controlados por el maestro, comenzaron

65 Luis José Guanochanga, entrevista personal, 11 de abril de 2013, Latacunga. 
a restringirse, produciéndose contradicciones entre algunos profesores y los comuneros. (DINEIB 1991, 29)

La problemática anterior es interesante por cuanto permite visualizar el hecho de que la creación de la jurisdicción de EIB significó no solo fuertes cambios a nivel de la estructura del MEC y una redefinición de las relaciones de poder construidas entre los docentes indígenas y los docentes blanco-mestizos, sino también un cambio importante a nivel de la organización del poder en varias comunidades rurales $\mathrm{y}$, de manera particular, de la relación de poder construida entre el educador y los comuneros. No debemos olvidar que, a nivel de las zonas rurales, el educador ha sido siempre un actor con mucho poder e influencia.

Luego de un año de visitas y diálogos, la DINEIB generó una nueva lista de escuelas de la jurisdicción de EIB, pero esta vez considerando la voluntad de las instituciones educativas de pertenecer a aquella. Para el caso de la provincia de Cotopaxi, el número de instituciones bajó a menos de la mitad, pues muchas de las que fueron inicialmente seleccionadas solicitaron regresar a la jurisdicción de educación hispana.

Desde el punto de vista de Luis José Guanochanga, ${ }^{66}$ si bien la reducción del número de instituciones fue un golpe fuerte para la EIB y para el trabajo que se venía haciendo tanto a nivel provincial como local, el hecho de haber dejado en libertad a las comunidades para que decidieran sobre su pertenencia fue una decisión acertada, pues se terminaron quedando en la jurisdicción de EIB las comunidades y escuelas que sintonizaban con la propuesta y que estaban interesadas en contribuir a la construcción de la educación en sus comunidades a nivel provincial.

El otro tema prioritario relacionado con la conformación de la Dirección Provincial tenía que ver con el recurso docente. La implementación de la EIB en la provincia requería, con urgencia, consolidar una planta docente con el perfil adecuado para dicho tipo de educación. El criterio definido por la DINEIB para la selección de docentes era que se debían priorizar, en primer lugar, a profesionales formados en educación 
y bilingües, y, en segundo lugar, a bachilleres en otras ramas del saber pero bilingües, con el objetivo de formarles en el área pedagógica. ${ }^{67}$

A diferencia de otras provincias, y similar a lo que ocurría en Carchi, Pichincha, Tungurahua y Azuay, en Cotopaxi había muy pocos indígenas con formación en educación y, de igual manera, muy pocos indígenas con título de bachiller en otras ramas del saber (DINEIB 1991). Para salvar la situación, se optó por dar nombramientos a profesionales de la educación y bachilleres bilingües de otras provincias, ${ }^{68}$ así como aprovechar a los numerosos educadores comunitarios que laboraban, desde tiempo atrás, con bonificaciones del Programa de Alfabetización de Adultos, muchos de ellos, educadores comunitarios del mismo SEIC. ${ }^{69}$

\section{Las tensiones y conflictos desatados}

La creación de la Dirección Provincial y la construcción de la jurisdicción en Cotopaxi no solo supuso un conjunto de retos sino que fue altamente conflictivo, pues tuvo fuertes detractores, entre los que destacaron los funcionarios y docentes de la Dirección Provincial de educación hispana, en especial aquellos docentes que en el proceso de selección de las escuelas quedaron de un momento a otro en la jurisdicción intercultural bilingüe, así como los directivos de la Unión Nacional de Educadores (UNE) de la provincia.

Dos eventos centrales que dan cuenta de las tensiones que se vivieron en Cotopaxi durante el primer año de vida de la DIPEIB, además de los conflictos cotidianos ya relatados, fueron el secuestro del director de la DINEIB en Latacunga y la marcha de respaldo a la EIB en esta ciudad. Relatamos brevemente en qué consistieron cada uno de ellos.

Días después de la designación de Luis José Guanochanga como director provincial, el director de la DINEIB fue invitado por el director de la Dirección de Educación hispana de Cotopaxi a una reunión de trabajo en Latacunga. En dicha reunión iban a participar, de acuerdo a

67 Luis Montaluisa, entrevista personal, 20 de marzo de 2013, Quito.

68 La mayor parte era de la provincia de Chimborazo. Amable Hurtado, entrevista personal, 23 de mayo de 2014, Pujilí.

69 Luis José Guanochanga, entrevista personal, 11 de marzo de 2013, Latacunga. 
la comunicación del director provincial de Educación hispana, sus supervisores; el propósito era ponerse al tanto de la creación de la nueva dirección. En la práctica, a la reunión asistieron funcionarios de la Dirección hispana y, además, cientos de docentes de las escuelas hispanas, que se dedicaron a insultar al director de la DINEIB, a descalificar a la educación indígena y a presionar al director para que solicitara la derogación del decreto de creación de la DINEIB. Leamos cómo el mismo director nacional relata lo acontecido:

Días después de la designación del director provincial de EIB de Cotopaxi, el director de la Dirección hispana [de Cotopaxi] de ese momento me llama y me dice "vea, los señores supervisores quieren información sobre la creación de esta nueva dirección, y yo le pido que usted venga a informarles". Si pues, yo cogí el bus ahí en el Cumandá (qué pensar que teníamos carro en ese tiempo, ¡nada!, viáticos ipeor!), y viajé a Latacunga. Cometí la imprudencia de no pasar por el MICC, fui directamente y solo. "Señor director estoy aquí, a su llamado". El director dice: "Sí, aquí están los profesores, no sé cómo es que se han enterado, no solo están aquí los de la planta (yo pensé que solo iban a estar los de la supervisión de la planta, 30 o 40 personas) pero han llegado muchos profesores que quieren oírle". Había cerca de 500 profesores. Entonces habían hecho toda una reunión en un salón enorme. Y comenzó el griterío: “¡abajo la educación bilingüe!”, “¡abajo los indios!”, “¡abajo...!”.

Y cuando yo entré saltaron, gritaron y de todo. El director provincial dice "vean señores profesores, aquí está el director nacional, pregúntenle no más y ¡cogió y se fue!". Entonces, todo el santo día me tuvieron puteándome. Entonces, yo también ya me calenté y les hablaba en kichwa. Entonces eso les daba más coraje a ellos: “¡ve, habla en cristiano!", me decían, ya puedes imaginarte. Me dijeron de todo: "incapaz, tienes que hacer que este momento se derogue ese decreto", "analfabeto".

Ya después de que no tenían qué más decir, y ya era algo así como las cuatro de la tarde, dicen: " $i y$ para que te des cuenta de que los propios indígenas te niegan y te desprecian, aquí te van a hablar los compañeros indígenas!". Entonces, les dan la palabra a unos mashis que habían ido, que les habían llevado diciéndoles que iban a pedir un puente al Consejo Provincial. Entonces, habla un mashi, y el mashi dice: "Señores profesores, porque ustedes llegan el martes y se van el jueves, por eso hemos pedido la creación de la educación bilingüe", después toma la palabra otro y lo mismo, defiende a la educación bilingüe. Es que eran 
compañeros, pues. Se les dio la vuelta la reunión a los de la Dirección hispana, y ahí sí pude salir del salón, porque al principio, en el momento del griterío y los insultos, yo pensé salir, pero acaso que me dejaron. ${ }^{70}$

Este evento no fue aislado, pues se repitió en varias provincias del país con diferentes matices y niveles de violencia, y dio cuenta del malestar que la creación de la DIPEIB generó entre los funcionarios y profesores de la jurisdicción de educación hispana y los representantes de la UNE.

El segundo evento de relevancia fue la marcha de respaldo a la EIB que tuvo lugar en Latacunga, en junio de 1989. La marcha tuvo como antecedente varios desplantes hacia los funcionarios de la Dirección Provincial y docentes de las escuelas indígenas, por parte de los funcionarios y docentes de la Dirección de Educación hispana y también por parte de miembros de la UNE de Cotopaxi.

El 22 de junio apareció en La Gazeta, la siguiente convocatoria a la marcha, la cual da cuenta del clima que se vivía en el momento así como de su sentido:

Unidos para respaldar nuestra propia educación

A lo largo de la historia universal, la educación fue un privilegio para los libres, para los nobles, para el grupo minoritario cuyo interés era defender su poder, su ideología para dominar y tener más.

Y en nuestro país, a raíz de la llegada de los incas, luego los españoles, los hacendados, el grupo dominante siempre estuvo convencido de que no era necesario ofrecer educación al indígena, lo más importante es que trabaje la tierra del patrón.

Es doloroso decir, pero en la actualidad, hay muchas personas "preparadas" que piensan con la cabeza del conquistador o del patrón; que no aceptan el hecho de que los mismos indígenas sean capaces de llevar adelante un proceso educativo en la lengua materna, simplemente porque tienen muy clavado un complejo de superioridad y porque viven falsamente engañados creyendo en la incapacidad de los indígenas. Incluso a nivel gubernamental, nunca hubo una política educativa acorde a la realidad del Pueblo Indígena; siempre se intentó "integrar al indio a la cultura" despojándolo de su cultura, presentando valores ajenos 
que provocaron que el indígena llegue a autodespreciarse, a sentirse inferior a los mestizos.

Apenas en esta última década y gracias al aporte, a la reflexión de algunas experiencias de Educación Indígena y organizaciones indígenas han ido surgiendo aportes con los cuales la CONAIE ha defendido las políticas educativas que orientan la educación indígena. Así pues, la Educación Indígena se propone fortalecer la identidad cultural, fortalecer los procesos organizativos, fomentar la participación de la comunidad en el proceso educativo y de desarrollo.

Y fue el 15 de noviembre de 1988, cuando se firmó el decreto 203 y consta en el registro oficial número 66 , decreto mediante el cual nació la DIRECCIÓN NACIONAL DE EDUCACIÓN INDÍGENA y posteriormente el 19 de abril de 1989, se posesionó oficialmente a los directores provinciales de educación indígena.

Este acontecimiento es motivo de celebración, porque en torno a este hecho cobran vida nuestras máximas aspiraciones: queremos que la educación bilingüe sea motivo de unidad del Pueblo Indígena, que fortalezca el MICC y que la educación sea el semillero de nuevos dirigentes que sean conscientes, preparados y que no traicionen a su Pueblo, y herramienta para vencer la pobreza.

Por otra parte, vale la pena anotar que el Director Nacional de Educación Indígena es el Lic. Luis Montaluisa y Director Provincial de Educación Indígena es Luis José Guanochanga, ambos son cotopaxenses y tenemos la seguridad de que pondrán nuevas bases en la construcción de nuestra propia educación.

Todo esto es motivo de alegría y esta hay que celebrarla, así pues, este viernes 23 de junio vendrán delegaciones indígenas provenientes de los cantones: Pujilí, Saquisilí, Pangua, Latacunga y Salcedo [...] niños, mujeres, hombres, saldrán a pie, en mula, en carro, todos aportando de su propio bolsillo, porque esta no es una manifestación politiquera sino una celebración por un derecho alcanzado y una gran responsabilidad por asumir y respaldar.

Este día caminaremos por las calles del casco urbano, con música, con alegría; luego en la plaza de Santo Domingo se desarrollará un Programa en el cual diremos nuestra palabra, se posesionará ante el pueblo indígena a nuestro director provincial, expresaremos nuestra gratitud a quienes nos han acompañado en nuestro caminar, se hará el lanzamiento de un libro escrito por los Educadores Comunitarios del SEIC y rendiremos homenaje a varios líderes quienes han luchado por la tierra y por la educación de nuestro Pueblo Indígena de Cotopaxi. 
De manera, que al cumplir los 500 años de resistencia indígena, queremos que cese la discriminación, la opresión, que se reconozca el derecho que tenemos a una vida digna, porque el derecho conquistado lo defenderemos con unidad y trabajo. (La Gazeta 1989)

La marcha fue multitudinaria y dejó estupefacta a la población blanco-mestiza de Latacunga. En la marcha se posesionó simbólicamente a Luis José Guanochanga frente a la población indígena (la posesión oficial había sido dos meses antes) y se aprovechó para legitimar el proceso con la presencia de las autoridades del MEC. Rodrigo Martínez relata de la siguiente manera el acontecimiento:

Después de cinco meses de reflexión y planificación a nivel de promotores del SEIC y sus comunidades de base, la presencia indígena en el casco feudal de Latacunga hizo temblar a la población mestiza. El casco urbano amaneció pintado con frases en kichwa y castellano demandando respeto a la cultura indígena, quinientos años de opresión. ¡Basta carajo!, ¡Respeta la educación indígena!, ¡Adelante SEIC!, etc. y a partir de las cuatro de la mañana, la Casa Campesina Juan Pablo II y luego la Plaza del Salto se llenó de indígenas (hombres, mujeres y niños), alrededor de cinco mil personas provenientes de 65 comunidades. Llegaron con pancartas, música, danza y frases cargadas de profunda reflexión que hicieron temblar a Latacunga. Se tomaron la plaza de Santo Domingo, donde solamente y en presencia de las autoridades eclesiásticas y civiles de la provincia se desarrolló la ceremonia del "varayuc" en el cual el director nacional de Educación Intercultural Bilingüe entregó la vara de mando al director provincial de Educación Intercultural Bilingüe de la provincia. Inolvidable fue el mensaje del Arq. Alfonso Calderón, asesor de la presidencia en asuntos indígenas, quien exaltó festivamente la presencia del pueblo indígena. Él dijo acertadamente "de un indio suelto, hasta un simple controlador de bus se burla, pero cuando el pueblo indígena está unido, hasta los gobiernos tiemblan”. (Martínez y Burbano 1994, 134)

Vale destacar que esta marcha tuvo lugar pocos meses antes del Levantamiento del Inti Raymi de 1990, y que fue, según el padre José Manangón, ${ }^{71}$ uno de sus antecedentes. Recordemos que entre las dieciséis

71 Padre José Manangón y Mery Martínez, entrevista personal, 10 de abril de 2014, Quito. 
demandas planteadas por los indígenas en el levantamiento de 1990 estaba la entrega de recursos permanentes para el funcionamiento de la EIB (Moreno y Figueroa 1992).

Con esta marcha se cerró el período de conflictividad de alto nivel en la provincia, aunque no las tensiones y problemas. Las tensiones continuaron durante los siguientes años conforme la jurisdicción de la EIB se iba consolidando en la provincia. Y es que su institucionalización significó el reforzamiento de la frontera étnica (Barth 1976) que se venía fraguando desde hace dos décadas como resultado de la emergencia de las escuelas indígenas, aunque con una diferencia importante con relación a los años anteriores: el poder y la presencia de los indígenas era mucho mayor.

\section{Funciones y frentes de trabajo de la DIPEIB-C}

Hasta aquí hemos hecho referencia al proceso de creación y consolidación de la DIPEIB y a los conflictos que aquello desató en el campo educativo. Pero, ¿cuáles fueron las responsabilidades que la Dirección Provincial asumió y pasó a desempeñar en el día a día?, ¿qué áreas del ámbito educativo pasaron a estar bajo su control?

\section{Funciones y responsabilidades}

Como se adelantó líneas antes, la DIPEIB era, en la práctica, la encargada de administrar la EIB en los diferentes cantones de la provincia de Cotopaxi y propender a su continuo mejoramiento. En calidad de tal, la dirección pasó a controlar un abanico importante de funciones que contemplaban desde las más básicas y rutinarias como, por ejemplo, tramitar las solicitudes de permiso de los docentes o receptar las calificaciones de los estudiantes, hasta las más delicadas y complejas como la formación del recurso docente o asegurar la implementación de un currículo cultural y lingüísticamente apropiado en las instituciones de educación de su jurisdicción. ${ }^{72}$

72 Para el desarrollo de esta parte hemos usado los dos planes estratégicos de desarrollo de la DIPEIB-C y un documento sobre el tema preparado por Amable Hurtado (2015), su exdirector, a pedido nuestro. 
En términos generales podemos decir que las funciones centrales de la Dirección Provincial se dividieron en dos grandes áreas: las administrativas y las técnicas-educativas. Entre las principales funciones administrativas estaban aquellas relacionadas con el manejo del recurso humano y las que tenían que ver con la gestión de los bienes materiales y tecnológicos.

En el ámbito de los recursos humanos la responsabilidad fundamental de la Dirección Provincial era asegurar el reclutamiento del recurso humano adecuado para el trabajo educativo y propiciar su estabilidad y bienestar, comprendía la selección y contratación de nuevos docentes, la tramitación de nombramientos para antiguos docentes, la aplicación de estímulos y sanciones, el despido, el acenso en el escalafón, la gestión de los permisos, licencias y demás solicitudes de los docentes, y el pago de sueldos.

Por otro lado, estaban las funciones relacionadas con la provisión de recursos materiales y tecnológicos para el normal funcionamiento de la Dirección Provincial, entre las que se incluía la compra de bienes muebles e inmuebles y su mantenimiento periódico.

En el área técnica-educativa, la Dirección Provincial tenía bajo su responsabilidad un conjunto de funciones que tenían como propósito central asegurar el desarrollo de la educación indígena en la provincia y propender a su mejoramiento: destacaban la formación docente, el desarrollo curricular y la supervisión educativa.

En el ámbito de la formación docente la responsabilidad principal era propiciar la cualificación del recurso docente de las escuelas y colegios de la jurisdicción de EIB, y consideraba tanto aquellos procesos de formación de largo aliento (estudios de bachillerato, formación técnica y licenciatura) como la formación continua mediante cursos orientados a actualizar a los docentes en temas clave para el trabajo educativo del día a día.

En el campo del desarrollo curricular la responsabilidad prioritaria era contextualizar la propuesta de la EIB generada a nivel nacional y propiciar su implementación en las escuelas de la jurisdicción, y contemplaba, entre otras actividades, socializar la propuesta curricular con los directivos de las escuelas y los docentes, definir directrices para su 
implementación, el acompañamiento a los docentes y producir material que permitiera su concreción en el aula.

Finalmente, en el ámbito de la supervisión educativa la responsabilidad de la dirección era velar porque el trabajo de las escuelas y colegios de la jurisdicción se ajustara a las directrices y parámetros nacionales y provinciales, y asesorar y apoyar a sus directivos y docentes en la implementación de la EIB en la provincia.

Para el trabajo del día a día la dirección contaba con un equipo de funcionarios organizados en cinco departamentos claramente diferenciados y que respondían al mandato del director provincial: el Administrativo-Financiero, Planeamiento, Formación Docente, Educación Popular Permanente y Supervisión. Cada uno de estos departamentos contaba, a su vez, con una estructura interna propia para su labor diaria, siendo el Administrativo-Financiero el departamento con la estructura más compleja por todas las funciones que estaban a su cargo.

Si bien es cierto que la estructura orgánica de la Dirección Provincial cambió muchas veces a lo largo de sus veinte años de vida, ya sea porque un departamento se dividía en varios departamentos, o porque dos de ellos se fusionaban en uno solo, o porque una de las dependencias de un departamento se convertía, de un momento a otro, en un departamento diferente; además, en términos generales, los departamentos centrales se mantuvieron en el tiempo.

Ahora bien, en el día a día las funciones señaladas no se cumplieron como se hubiera esperado, pues estuvieron atadas a diferentes tipos de condicionamientos. Tres fueron los principales factores que limitaron el trabajo de la Dirección Provincial en el día a día: el número de funcionarios, su perfil y el financiamiento.

Respecto al primer punto, la mayor parte de directores provinciales entrevistados pusieron sobre la mesa el tema del reducido equipo con el que la Dirección Provincial contaba para todas las responsabilidades y funciones que tenía que cumplir a diario, y, de manera especial, para el trabajo de supervisión de las escuelas y colegios de la provincia. Sobre este último punto, la Dirección Provincial tuvo un promedio de cuatro supervisores para visitar más de 120 instituciones educativas (entre escuelas y 
colegios) que formaban parte de la jurisdicción de EIB. Si a eso añadimos el tema de la dispersión de las escuelas, se entiende por qué a ciertas escuelas los supervisores llegaban, con suerte, una sola vez al año. ${ }^{73}$

El otro punto tenía que ver con el perfil de los funcionarios. Si bien es cierto que desde un inicio la dirección hizo esfuerzos importantes por reclutar a funcionarios con el perfil idóneo para las diferentes funciones, y que se preocupó por la formación del equipo; de igual forma, para el trabajo cotidiano, el perfil de los funcionarios no siempre fue el más adecuado. ${ }^{74}$

Dicha debilidad fue sentida especialmente en aquellas funciones que demandaban una experticia especial como era el tema de la capacitación y actualización de los docentes y el asesoramiento in situ. Y es que, a diferencia de la educación para la población mestiza, la EIB requería de un plus a nivel de la formación y experticia de los funcionarios, pues en dicho modelo educativo el componente educativo-pedagógico, de por sí complejo, siempre estaba atravesado por el tema de la interculturalidad y el bilingüismo.

Es en el marco de lo anteriormente expuesto que se debe entender uno de los reclamos permanentes de los educadores de las escuelas de la jurisdicción de EIB con relación a los funcionarios de la dirección. El principal cuestionamiento iba dirigido al hecho de que los funcionarios no contaban con el conocimiento necesario para el trabajo que les tocaba hacer, aspecto que muchas veces terminaba provocando serias confusiones en el trabajo cotidiano de las escuelas, de manera especial a nivel de la asesoría de los supervisores (Tibán 2008).

Finalmente, estaba el financiamiento. Similar a lo ocurrido con el primer tema, todos los directores provinciales plantearon de manera enfática lo del reducido financiamiento con el que la Dirección Provincial contaba para su gestión diaria y el desarrollo de los diferentes frentes de trabajo. El financiamiento entregado por el Estado alcanzaba

73 Francisco Pastuña, entrevista personal, 16 de mayo de 2014, comunidad del Quilotoa, parroquia Zumbahua, cantón Pujilí.

74 Roberto Allauca, entrevista personal, 18 de abril de 2013, Latacunga. 
exclusivamente para cubrir los gastos de administración, el mantenimiento de los bienes y el pago a los funcionarios y personal docente.

Para el desarrollo de todas las iniciativas que requerían contratación de personal externo o rubros para su implementación (un programa de formación para los docentes, por ejemplo), la dirección siempre se vio en la necesidad de buscar financiamiento externo, fundamentalmente de las agencias de cooperación internacional. Basta revisar los dos planes de desarrollo generados por la DIPEIB-C para evidenciar el peso que tenía el financiamiento externo, pues la gran mayoría de actividades de las diferentes áreas de trabajo (formación docente, mejoramiento de infraestructura, desarrollo curricular, etc.) se las proyectaba realizar con él.

El problema con ese financiamiento era que no podía ser utilizado libremente por la Dirección Provincial, pues las agencias de cooperación internacional, al igual que cualquier otro actor involucrado en el tema, tenían una agenda propia que priorizaba ciertos frentes de trabajo, así como determinadas zonas y grupos poblacionales en desmedro de otros; lo que muchas veces terminaba provocando cambios importantes en la planificación inicial de la dirección. ${ }^{75}$

Principales frentes de trabajo

Ahora bien, ¿cuáles fueron los principales frentes de trabajo de la Dirección Provincial, más allá de la gestión cotidiana relacionada con el manejo del recurso docente, el seguimiento académico y el procesamiento de las solicitudes presentadas por estudiantes y padres de familia de las escuelas de la jurisdicción de la EIB? Basados en las entrevistas realizadas a los directores provinciales y a la revisión de los planes e informes de trabajo de la Dirección Provincial, podemos decir que sus principales frentes de trabajo durante sus veinte años de vida fueron dos: la formación de los docentes y el desarrollo curricular; ambos de una importancia capital por cuanto permitían, desde la perspectiva de los mismos directores y equipos de las direcciones provinciales, generar 
las condiciones básicas para implementar en la zona una educación con pertinencia social, cultural y lingüística.

En cuanto al primer punto, el de la formación docente, fueron varias las iniciativas impulsadas por la Dirección Provincial en esta materia, pues siempre hubo la certeza de que la implementación de la EIB y su fortalecimiento continuo requerían necesariamente de docentes con los conocimientos y las habilidades adecuadas para llevar adelante una modalidad de educación de este tipo. ${ }^{76}$

A manera de paréntesis, vale decir que la preocupación por la formación del recurso docente en el ámbito de la EIB ha sido tema generalizado y recurrente en los países latinoamericanos, y ayuda a comprender la gran cantidad de iniciativas desplegadas por los Estados, las universidades, las oenegés y organizaciones indígenas, tanto bajo la modalidad de cursos rápidos de formación continua como de procesos de formación de largo alcance: licenciaturas e inclusive maestrías.

En un primer momento, el énfasis de la Dirección Provincial estuvo en que los docentes de la jurisdicción de EIB se profesionalizaran pues, como vimos, cuando se creó la Dirección Provincial en 1989, el grueso de los docentes no había ni siquiera alcanzado la formación de bachillerato: de los 138 profesores que en ese momento laboraban en el nivel primario, apenas el 7 \% contaba con título de bachiller (Martínez y Burbano 1994).

Con dicho objetivo en mente, la Dirección Provincial gestionó un convenio con el Instituto Pedagógico Intercultural Bilingüe Quilloac de Cañar, para que los profesores de la jurisdicción concluyeran el bachillerato y luego se formaran como profesores primarios bilingües. ${ }^{77}$ Para 1993, 89 profesores de la jurisdicción se graduaron como bachilleres en Ciencias con especialidad en EIB y 64 profesores obtuvieron el título de profesores primarios bilingües (Martínez y Burbano 1994).

En un segundo momento se puso énfasis en la formación a nivel de licenciatura. ${ }^{78}$ Para 1994 la UPS ya había abierto en Zumbahua

76 Édgar Guashca, entrevista personal, 10 de abril de 2013, Latacunga.

77 Amable Hurtado, entrevista personal, 23 de mayo de 2014, Pujilí.

78 Roberto Allauca, entrevista personal, 18 de abril de 2013, Latacunga. 
la licenciatura de EIB para los docentes del SEIC, que fue aprovechada también por muchos docentes del resto de escuelas de la jurisdicción. No hubo convenio alguno entre la Dirección Provincial y la UPS, pero sí un acuerdo tácito pues, como veremos en el siguiente capítulo, varias de las personas que laboraban en la Dirección Provincial eran parte del equipo que en un inicio impulsó dicho programa de licenciatura.

Debido a los problemas que los educadores tenían para cursar esta licenciatura, en especial por la distancia (en los primeros años la licenciatura operó en Zumbahua), la Dirección Provincial gestionó un convenio con la Universidad Técnica de Ambato para la formación de los profesores a nivel de licenciatura. Gracias a dicho convenio un grupo importante de profesores de la jurisdicción se graduó de licenciados en Ciencias de la Educación con mención en Didáctica de las Ciencias Sociales. ${ }^{79}$

El trabajo de la Dirección Provincial en materia de formación docente no se limitó a la gestión y concreción del convenio, sino que incluyó la gestión de becas para los profesores (fundamentalmente con la cooperación internacional) e incluso el apoyo mediante la concesión de comisión de servicios, aspectos sin los cuales los docentes difícilmente hubieran podido llevar adelante sus estudios y titularse. ${ }^{80}$ Un ejemplo de lo anterior fue el permiso y apoyo que la dirección dio a varios funcionarios y educadores para que cursaran la licenciatura de Lingüística Andina y Educación Bilingüe ofertada por la Universidad de Cuenca.

A estas iniciativas de formación hay que añadir todo el trabajo desarrollado por la Dirección Provincial a nivel de formación continua y actualización docente. En esta línea se enmarcan todos aquellos cursos cortos sobre lengua, currículo, didáctica, etc., destinados a poner al día a los docentes en las herramientas básicas para el trabajo del día a día en el aula. También en esta línea se ubican todos aquellos cursos organizados específicamente para el acenso de los profesores en el escalafón, que contemplaban un total de 120 horas e incluían tres asignaturas: lengua kichwa, herramientas pedagógicas y material didáctico. ${ }^{81}$

79 Amable Hurtado, entrevista personal, 23 de mayo de 2014, Pujilí.

80 Édgar Guashca, entrevista personal, 10 de abril de 2013, Latacunga.

81 Amable Hurtado, entrevista personal, 23 de mayo de 2014, Pujilí. 
La formación del recurso docente fue, desde la perspectiva de los directores provinciales, no solo el principal frente de trabajo de la Dirección Provincial en el transcurso de sus dos décadas de vida, sino el frente en el que más resultados positivos se generaron, apreciación que se confirma con algunos datos estadísticos. Si tomamos como referencia 2006 y lo comparamos con 1989, año en el que la Dirección Provincial inició sus labores, se puede constatar grandes avances en dicho ámbito, pues a diferencia de 1989, en el que más del $90 \%$ de los profesores no contaba ni siquiera con título de bachillerato (Martínez y Burbano 1994), en 2006 el 74 \% de los profesores de la jurisdicción contaba ya con título de bachiller, y de estos, el $71 \%$, contaba, además, con una titulación de educación superior: profesor primario, licenciatura, maestría o doctorado de tercer nivel (DIPEIB-C 2007).

Estos datos adquieren mayor relevancia si consideramos el total de docentes de cada año: a diferencia de 1989, en el que la jurisdicción de EIB estaba conformada por 108 docentes (Martínez y Burbano 1994), en 2006 la jurisdicción llegó a contar con un total de 491 profesores (DIPEIB-C 2007). Así, cuando decimos que en 2006 el 73 \% de los docentes llegó a tener título de bachillerato, estamos haciendo referencia a un total de 364 docentes, número importante si se lo compara con el total de docentes con los que la Dirección Provincial inició sus funciones.

Para cerrar este punto conviene señalar que el tema de la formación del recurso docente sufrió un giro importante con la implementación del proyecto de las Redes de los Centros Comunitarios de EIB en 2000, pues dicho proceso dejó de estar centralizado en la Dirección Provincial y pasó a manos de estas redes. Este tema y el proceso de formación docente en ese marco, en particular, será tratado en detalle en el siguiente capítulo.

En lo que al desarrollo curricular se refiere, el otro frente de trabajo priorizado, el trabajo de la Dirección Provincial de igual forma fue importante, aunque el impacto alcanzado fue mucho menor que el logrado en el ámbito de la formación docente. Para entender el trabajo desarrollado en este frente es necesario, sin embargo, hacer un breve 
paréntesis para referirnos al tema del Modelo del Sistema de Educación Intercultural Bilingüe (MOSEIB).

Como se analizó en el apartado anterior, entre las responsabilidades entregadas a la DINEIB en el marco de su proceso de creación, estaba la definición de un currículo propio para la EIB. El argumento central era que - y la experiencia había enseñado de sobra a las organizaciones indígenas - la implementación de una educación apropiada para la población indígena requería no solo de la formación de docentes especializados en el tema, sino también de la construcción de un currículo que recuperara las particularidades culturales de los pueblos indígenas y que respondiera a sus necesidades y se alineara con sus intereses y expectativas.

Ya en 1989, a los pocos meses de la creación de la DINEIB, sus funcionarios enfatizaban en las siguientes necesidades:

- Elaborar un currículum que conserve y respete los conocimientos de la ciencia etnológica y que esté en armonía con la cosmovisión indígena.

- Incorporar a los contenidos los esquemas lógicos, el concepto de tiempo y espacio y los sistemas de clasificación de la ciencia indígena y los elementos que conforman su cultura.

- Definir planes y programas con relación a las necesidades, intereses y expectativas de los pueblos indígenas. (Mashinkiash, Morocho et al. 1990, 208)

El trabajo de diseño curricular inició tan pronto como fue creada la DINEIB y no partió de cero, pues había todo un acumulado que se había generado e inclusive validado en las experiencias de educación indígena anteriores, siendo lo más desarrollado, desde el punto de vista técnico, lo que se había producido en el marco del Proyecto de Educación Bilingüe Intercultural impulsado por la Cooperación Alemana, y el Proyecto MACAC del Centro de Investigaciones de Educación Indígena. En ambos casos se había avanzado mucho a nivel de la fundamentación teórica de la dimensión intercultural y bilingüe del modelo de educación indígena, en la definición de propuestas macro y microcurriculares culturalmente 
pertinentes, y en la producción de módulos y materiales para el trabajo diario en el aula. ${ }^{82}$

El trabajo de diseño curricular significó la organización de varios talleres a nivel nacional en los que participaron activamente funcionarios de la DINEIB, y líderes indígenas y funcionarios de la cooperación internacional. Supuso tensiones fuertes sobre el enfoque de la propuesta y la forma de concretarla a nivel de las diferentes áreas de conocimiento (Valiente y Kuper 1998). Finalmente, el 31 de agosto de 1993, cuatro años después de creada la DINEIB, el MOSEIB fue aprobado por el MEC.

El MOSEIB es una propuesta que, como su nombre lo indica, caracteriza el modelo de la educación indígena del país y va mucho más allá de los contenidos de cada una de las áreas académicas. Como tal es una propuesta que especifica los antecedentes de la EIB, sus objetivos, principios, estrategias, modalidad de trabajo, calendario, metodología, forma de evaluación, y, finalmente, los contenidos de cada una de las áreas académicas por nivel. El MOSEIB contempló seis áreas académicas: lengua indígena, español como segunda lengua, historia, matemáticas, cultura física y crecimiento personal, y ciencias aplicadas y artes (DINEIB 1994).

Al poco tiempo de oficializado, el MOSEIB se convirtió en un documento emblemático tanto a nivel nacional como regional, pues era la constatación de que era posible pensar y llevar adelante un modelo de educación diferenciado para los pueblos indígenas, por un lado, y que era posible que los mismos pueblos indígenas definieran su propio modelo educativo, acorde con su realidad y expectativas, por otro.

Una vez oficializado el MOSEIB, el siguiente paso fue socializarlo entre los funcionarios de la planta central y los funcionarios de las direcciones provinciales, pues de eso dependía la apropiación de la propuesta y su posterior implementación en las escuelas de la jurisdicción. El proceso de socialización a nivel provincial consistió en visitas a las direcciones y talleres con los equipos de funcionarios de aquellas, para explicar el nuevo modelo educativo y las directrices para su implementación en el aula.

82 Para una discusión detallada sobre la historia, desarrollo y aportes del proyecto EBI y del proyecto MACAC se puede revisar el texto de Francesco Chiodi, La educación indígena en Ecuador (1990). 
El trabajo de socialización a nivel de las escuelas y las comunidades, y el trabajo de velar por su implementación en el trabajo diario en el aula quedaron en manos de las direcciones provinciales. ${ }^{83}$

Luego de este breve paréntesis podemos regresar al trabajo desempeñado por la Dirección Provincial de Cotopaxi en materia curricular. En años anteriores a la aprobación del MOSEIB el trabajo de la Dirección Provincial en este ámbito no fue mayor pues, como vimos arriba, no solo que había otros frentes más urgentes, sino que no era necesario puesto que el grueso de las escuelas de la jurisdicción de EIB (las del SEIC, del proyecto de EIB y del proyecto MACAC) contaban con su propio currículo y materiales para el trabajo en el aula.

Con la aprobación del MOSEIB, el trabajo de la Dirección Provincial en el ámbito curricular cambió radicalmente pues, al igual que las demás direcciones provinciales, tuvo que focalizar su atención en asegurar que este aterrizara en las aulas de las escuelas de la jurisdicción. Desde 1994 hasta 1999 el trabajo se centró en socializar el modelo en las escuelas y comunidades, en capacitar a los docentes para su aplicación en el aula, y en supervisar que las escuelas lo implementaran. ${ }^{84}$

A pesar de todo el esfuerzo y tiempo invertido, el impacto fue mínimo y el MOSEIB no llegó a concretarse en el día a día del aula de las escuelas de la jurisdicción. Varias fueron las razones para ello, la principal fue que la propuesta del modelo se quedó en un nivel macro (se llegó a definir las orientaciones generales y grandes contenidos que se debían trabajar a nivel de cada una de las áreas) y no proveyó las herramientas necesarias para aterrizar dichos contenidos en el día a día, a saber, la planificación microcurricular. Amable Hurtado, funcionario de la DIPEIB-C desde sus inicios y su director, recuerda los momentos iniciales de la aplicación del MOSEIB de la siguiente manera:

$\mathrm{Al}$ inicio, los mismos funcionarios no entendíamos hacia dónde caminar, no entendíamos, en definitiva, el modelo. El momento de querer

83 Entrevistas personales a Luis Montaluisa, 20 de marzo de 2013, Quito, y a Luis José Guanochanga, 11 de abril de 2013, Latacunga.

84 Entrevistas personales a Amable Hurtado, 23 de mayo de 2014, Pujilí, y a Édgar Guashca, 10 de abril de 2013, Latacunga. 
implementar en el aula como que sentíamos que algo faltaba. Los profesores nos decían: "vea aquí tenemos el modelo del sistema, el macrocurrículo, pero con los contenidos generales no podemos trabajar y ustedes nos piden que trabajemos dando valor a la interculturalidad, a los contenidos propios, a los ecosistemas". Y es que lo que hacía falta era el microcurrículo. ${ }^{85}$

Con base en esta experiencia, que se repitió en las demás provincias, la Dirección Provincial vio la necesidad ineludible de avanzar en la definición de la propuesta microcurricular del MOSEIB. Así, desde 2000 a 2005, el trabajo de la dirección se centró en la construcción de la propuesta microcurricular del modelo y en la producción de textos escolares que la acompañaran. En un inicio el trabajo fue impulsado desde la Dirección Provincial de Cotopaxi, con el apoyo técnico y financiero de Plan Internacional y CARE, pero con el paso del tiempo se involucraron las demás direcciones provinciales de la Sierra, y al final la misma DINEIB, que en un inicio no estaba del todo convencida. ${ }^{86}$

El trabajo significó para la Dirección Provincial largas jornadas de trabajo y supuso la participación activa y decidida de varios de sus funcionarios, así como la participación, para ciertos tramos, de los profesores de las escuelas de la jurisdicción, en especial para los momentos de validación de la propuesta y los textos.

Finalmente, en septiembre de 2004, luego de cuatro años de trabajo, se publicó el Rediseño curricular, documento que contempla la propuesta microcurricular de educación de la nacionalidad kichwa, y en el que se definen los objetivos de cada una de las seis áreas de estudio: kichwa, español, matemáticas, historia y geografía, ciencias aplicadas y cultura física; así como los temas que se debían trabajar en cada uno de los niveles de formación y las orientaciones metodológicas para el trabajo en el aula (DINEIB 2004). En 2004 también se publicaron los textos que acompañaban a la propuesta microcurricular: los Kukayos pedagógicos.

Con la propuesta lista, el trabajo de la Dirección Provincial se focalizó en socializarla en las escuelas y capacitar a los profesores para

85 Amable Hurtado, entrevista personal, 23 de mayo de 2014, Pujilí.

86 Édgar Guashca, entrevista personal, 10 de abril de 2013, Latacunga. 
su aplicación en el aula, hasta 2008, año en el que dicho frente fue interrumpido, pues comenzaron a llegar desde el Ministerio de Educación disposiciones de que se asumiera la malla de la educación hispana y sus textos escolares. ${ }^{87}$

Hasta aquí hemos hecho referencia a los dos frentes de trabajo más importantes de la Dirección Provincial durante sus veinte años de vida. Para cerrar este apartado haremos alusión a un frente más que, si bien no fue una línea de trabajo permanente, tuvo resultados interesantes que son muy bien valorados por los mismos funcionarios y demás actores de la EIB en la provincia. Nos referimos al proceso de evaluación de su calidad.

Desde siempre, contar con información fidedigna sobre la situación de la EIB en la provincia fue un requerimiento de suprema importancia para la gestión de la dirección, pues de ella dependía, en buena parte, la planificación y, de manera especial, los énfasis que se ponían en cada frente. En esta línea, siempre hubo la preocupación por mantener estadísticas actualizadas sobre el número de escuelas, de docentes, de estudiantes, el índice de deserción y la repitencia, entre otras. Sin embargo, nunca se llegó a contar con información precisa sobre las condiciones en las que se desarrollaba la educación en la provincia ni sobre los logros en materia educativa. ${ }^{88}$

Con miras a contar con una imagen clara y objetiva sobre la situación de la EIB, en 2000, conjuntamente con las direcciones provinciales de la Sierra, la DINEIB inició el trabajo de construcción y definición de una propuesta para evaluar la calidad de la EIB, proceso en el que apoyaron técnica y financieramente UNICEF y GTZ, en un primer momento, y Plan Ecuador en un segundo momento (DINEIB y DIPEIB-C 2006).

En septiembre de 2004 la DINEIB oficializó la propuesta de evaluación conocida como Sistema de seguimiento, monitoreo y evaluación (SISEMOE) de la EIB. Era toda una estrategia para evaluar tanto la situación de los centros educativos a nivel de su infraestructura y equipamiento como los logros de aprendizaje de los estudiantes en cuatro áreas: aprestamiento, kichwa, español y matemáticas. 
Al siguiente año, 2005, el sistema fue aplicado en todas las provincias de la Sierra. En la provincia de Cotopaxi la implementación estuvo a cargo de la DIPEIB con el apoyo de varias instancias, entre las que destaca Plan Ecuador y el FEPP. Para la evaluación de la calidad se trabajó con los 146 centros educativos que en ese momento formaban parte de la jurisdicción, mientras que para la evaluación de los logros de aprendizaje se trabajó con una muestra de veintiséis centros educativos, el $23 \%$ de los centros (DINEIB y DIPEIB-C 2006).

Finalmente, en 2006, luego de un trabajo intenso de sistematización e interpretación de la información recopilada, se armó el informe final de evaluación, que fue socializado en varios talleres en los que participaron directivos, docentes y padres de familia de la jurisdicción de EIB, así como líderes indígenas de la zona. El informe fue utilizado como un insumo clave por el equipo de la Dirección Provincial para elaborar el Plan de desarrollo de educación intercultural bilingüe de Cotopaxi, 2007-2017.

\section{Evolución de la jurisdicción de la EIB en la provincia}

Para cerrar el capítulo conviene dar una rápida mirada a la evolución de la jurisdicción de EIB de la provincia de Cotopaxi, pues nos da una idea clara de su crecimiento en las dos décadas de vida, así como el trabajo que tuvo que enfrentar la Dirección Provincial en el transcurso de los años.

Para este tema contamos con datos de tres años lectivos diferentes: 1989-1990, 1999-2000 y 2006-2007, y que cubren casi todo el período de vida de la dirección: 1989-2011. ${ }^{89}$ Hemos obtenido los datos del texto de Rodrigo Martínez (1994), de los dos planes estratégicos de desarrollo de la Dirección Provincial (el plan 2000-2005 y el plan 2007-2017), y del informe de la aplicación del SISEMOE en la provincia de Cotopaxi.

En términos generales se constata un crecimiento importante de la jurisdicción, tendencia que se la puede evidenciar a partir de tres

89 En 2011 se disolvieron las DIPEIB, y se dio paso al nuevo ordenamiento que contempla direcciones zonales, direcciones distritales y circuitos educativos. 
indicadores clave: el número de centros educativos, el número de estudiantes y el número de profesores. Sobre el primer punto, se puede evidenciar un crecimiento importante del número de los centros educativos en el transcurso de los diecisiete años en cuestión. En el año lectivo 1989-1990, año en el que se creó la Dirección Provincial, la jurisdicción de EIB estaba conformada por un total de 66 centros educativos (Martínez 252). Para el año lectivo 1999-2000, la jurisdicción contaba con un total de 112 instituciones educativas, de las cuales seis eran de educación media, y las demás de educación primaria; mientras que para 2007, la jurisdicción contaba con un total de 126 centros educativos, de los cuales seis continuaban siendo de educación media.

El aumento del número de los centros educativos se dio mediante tres vías: por la reactivación de las escuelas que por diferentes razones habían dejado de funcionar y que solicitaron adscribirse a la jurisdicción (este fue el caso, por ejemplo, de las escuelas de la zona de Panyatug), por el traspaso de escuelas que con el proceso de institucionalización quedaron adscritas a la jurisdicción hispana (fue el caso de varias escuelas ubicadas en el cantón Salcedo) (Martínez y Burbano 1994), y, por último, mediante la creación de nuevas escuelas y colegios por demanda de las mismas comunidades.

Se constata también un crecimiento importante del número de estudiantes de la jurisdicción: en el año lectivo 1989-1990 el número total de estudiantes de la jurisdicción era de 3 312. Para el año lectivo 1999-2000, diez años después, el número de estudiantes creció a 7 855, y para 2006-2007 el número llegó a 10 506. Es decir, se puede apreciar que, en el lapso de los diecisiete años considerados para el análisis, el número estudiantes de la jurisdicción de EIB creció en 200 \%, lo que da cuenta de la fuerte demanda que hubo por la educación en las zonas indígenas de la provincia.

A nivel de los docentes, actores clave del proceso, podemos constatar asimismo un crecimiento importante: en 1989 la jurisdicción de educación intercultural bilingüe contaba con un total de 108 docentes; para el año lectivo 1999-2000 el número ascendió a 312, y para el año lectivo 2006-2007, la jurisdicción llegó a contar con un total de 491 docentes. 
Nuevamente se puede evidenciar un crecimiento importante del número de docentes de la jurisdicción de EIB, presionado, como se revisó antes, por el acelerado crecimiento del número de estudiantes.

Los datos sobre el crecimiento de la EIB en la provincia de Cotopaxi son relevantes por sí mismos, pero más aún si consideramos la fuerte migración que experimentó la zona rural de la provincia durante el período en cuestión. Al igual que las zonas rurales de la demás provincias de la Sierra, y de manera especial aquellas con un alto porcentaje de población indígena, las zonas rurales de la provincia de Cotopaxi vivieron en las dos décadas de vida de la Dirección Provincial fuertes oleadas migratorias, resultado de lo cual muchas familias indígenas pasaron a vivir de manera permanente en Latacunga, Quevedo, Ambato e incluso Quito (Sánchez Parga 1991). Fenómenos de esta índole darían para pensar que la EIB iba a vivir una suerte de estancamiento en su crecimiento e inclusive momentos de decrecimiento.

Los datos también son importantes si consideramos la fuerte campaña de desprestigio promovida por los directivos y docentes de la educación hispana y la UNE, desde el nacimiento de la dirección hasta su disolución, aspecto que, si bien influyó en ciertas familias e inclusive en ciertas comunidades, vemos que, en términos generales, no provocó un traspaso masivo de los estudiantes desde las escuelas y colegios de la jurisdicción de EIB hacia las instituciones educativas de la jurisdicción hispana. 